\title{
TRANFORMAÇÃO, DIÁLOGOS E LINGUAGEM SOBRE AS MUDANÇAS CLIMÁTICAS
}

\author{
Izabel Cristina Petraglia \\ Universidade Metodista de São Paulo - UMESP (Brasil) \\ izabelpetraglia@terra.com.br·https://orcid.org/0000-0002-9003-8998 \\ Alfredo Pena-Vega \\ Institut Interdiscipliaire d'Anthropologie du Contemporain, EHESS-CNRS (França) \\ alfredo.pena-vega@ehess.fr $\cdot \underline{\text { https://orcid.org/0000-0002-4151-9146 }}$ \\ Mariangelica Arone \\ Grupo de Estudos e Pesquisas em Complexidade GEPEC/CNPq (Brasil) \\ angelicarone@yahoo.com.br·https://orcid.org/0000-0002-0734-1858 \\ Marcel Sena Fernandes \\ Grupo de Estudos e Pesquisas em Complexidade GEPEC/CNPq (Brasil) \\ marcel.sena@bol.com.br·https://orcid.org/0000-0002-2103-7676 \\ Conceição Aparecida Viude Fernandes \\ Grupo de Estudos e Pesquisas em Complexidade GEPEC/CNPq (Brasil) \\ viude@terra.com.br $\cdot$ https://orcid./org/0000-0002-3227-3973
}

\begin{abstract}
Resumo. Este artigo apresenta resultados parciais da pesquisa internacional em desenvolvimento intitulada "Pacto Mundial de jovens pelo clima" (em inglês: Global Youth Climate Pact) e um recorte, que se realiza no Brasil: "Mudanças climáticas na visão de estudantes de ensino médio, no Brasil”, em que promovemos diálogos e reflexões em relação à evolução das mudanças climáticas e ao compromisso necessário com o meio ambiente e com a cidadania planetária. Trata-se de um estudo em nível global e local que está nos possibilitando, no conjunto dos resultados parciais obtidos até o presente, perceber os valores, os sonhos e os comportamentos dos jovens para uma sociedade sustentável. Apresentamos, aqui, um recorte que aborda a conclusão da primeira fase da pesquisa, realizada em 2014 e 2015, com base nas investigações continuadas, sistematizações e divulgação de resultados que foram encaminhadas à COP21, em Paris, embora as suas propostas tenham também convergência com os encaminhamentos dos jovens de outros países participantes. Acreditamos ser importante conhecer como os jovens de diferentes regiões e diversificadas culturas sentem a magnitude das mudanças climáticas e a sua evolução, já que serão eles os gestores do Planeta, daqui a alguns anos. São essas prerrogativas e questões, cujas respostas estamos perseguindo, que justificam a relevância social e acadêmica desta pesquisa. O referencial teórico norteador é a epistemologia da complexidade, de Edgar Morin, e a pesquisa de abordagem inter e transdisciplinar adota técnicas multidisciplinares, tais como observação, entrevistas com gestores, grupos focais com estudantes, discussão cidadã entre os jovens (crowdsourcing).
\end{abstract}

Palavras-chave: Mudanças climáticas, estudantes, pesquisa, cidadania planetária.

\section{TRANSFORMATION, DIALOGUES AND LANGUAGE ON CLIMATE CHANGE}

\begin{abstract}
Este artigo apresenta resultados parciais da pesquisa internacional em desenvolvimento intitulada "Pacto Mundial de jovens pelo clima" (em inglês: Global Youth Climate Pact) e um recorte, que se realiza no Brasil: "Mudanças climáticas na visão de estudantes de ensino médio, no Brasil”, em que promovemos diálogos e reflexões em relação à evolução das mudanças climáticas e ao compromisso
\end{abstract}


necessário com o meio ambiente e com a cidadania planetária. Trata-se de um estudo em nível global e local que está nos possibilitando, no conjunto dos resultados parciais obtidos até o presente, perceber os valores, os sonhos e os comportamentos dos jovens para uma sociedade sustentável. Apresentamos, aqui, um recorte que aborda a conclusão da primeira fase da pesquisa, realizada em 2014 e 2015, com base nas investigações continuadas, sistematizações e divulgação de resultados que foram encaminhadas à COP21, em Paris, embora as suas propostas tenham também convergência com os encaminhamentos dos jovens de outros países participantes. Acreditamos ser importante conhecer como os jovens de diferentes regiões e diversificadas culturas sentem a magnitude das mudanças climáticas e a sua evolução, já que serão eles os gestores do Planeta, daqui a alguns anos. São essas prerrogativas e questões, cujas respostas estamos perseguindo, que justificam a relevância social e acadêmica desta pesquisa. O referencial teórico norteador é a epistemologia da complexidade, de Edgar Morin, e a pesquisa de abordagem inter e transdisciplinar adota técnicas multidisciplinares, tais como observação, entrevistas com gestores, grupos focais com estudantes, discussão cidadã entre os jovens (crowdsourcing).

Keywords: Climate changes, students, research, planetary citizenship.

\title{
TRANSFORMACIÓN, DIÁLOGOS Y LENGUAJE SOBRE EL CAMBIO CLIMÁTICO
}

\begin{abstract}
Resumen. Este artículo es sobre una investigación internacional en desarrollo titulada "Pacto Mundial de jóvenes por el clima" (en inglés: Global Youth Climate Pact) y un recorte, que se realiza en Brasil: "Cambios climáticos en la visión de estudiantes de enseñanza media, en Brasil ", En que promovemos diálogos y reflexiones en relación al problema del cambio climático y la necesidad del compromiso con el medio ambiente y la ciudadanía planetaria. Se trata de un estudio a nivel global y local que nos está posibilitando en el conjunto de los resultados parciales obtenidos hasta el presente percibir los valores, los sueños, y los comportamientos de los jóvenes hacia una sociedad sostenible. En el marco de las investigaciones continuas, sistematizaciones y divulgación de resultados que se remitieron a la COP21 en París, aunque presentamos una propuesta de convergencia con los países en desarrollo, encaminamientos de los jóvenes de otros países participantes. Creemos que es importante conocer cómo los jóvenes de diferentes regiones y diversificadas culturas perciben la magnitud del cambio climático y su evolución, ya que serán ellos los gestores del Planeta, dentro de algunos años. Esas prerrogativas y cuestiones, cuyas respuestas estamos persiguiendo y que justifican la relevancia social y académica de esta investigación. El referencial teórico orientador es la epistemología de la complejidad, de Edgar Morin y la investigación de enfoque inter y transdisciplinario adopta técnicas multidisciplinares, tales como observación, entrevistas con gestores, grupos focales con estudiantes y discusión ciudadana entre los jóvenes (crowdsourcing).
\end{abstract}

Palabras clave: Cambios climáticos, estudiantes, investigación, ciudadanía planetaria.

\section{Introdução}

Este artigo apresenta resultados parciais da pesquisa internacional em desenvolvimento intitulada "Pacto Mundial de Jovens pelo Clima" (em inglês: Global Youth Climate Pact) $)^{i}$ e um recorte, que se realiza no Brasil: "Mudanças climáticas na visão de estudantes de ensino médio, no Brasil", em que promovemos diálogos e reflexões em relação à evolução das mudanças climáticas e ao compromisso com o meio ambiente e com a cidadania planetária. Trata-se de um estudo em nível global e 
local que está nos possibilitando, no conjunto dos resultados parciais obtidos até o presente, perceber os valores, os sonhos e os comportamentos para uma sociedade sustentável, na perspectiva da juventude.

Diante do cenário dos últimos anos, muito tem se refletido sobre os problemas ambientais. É preciso ouvir, compreender, debater. A discussão em torno do tema "mudanças climáticas" nos leva a alguns pressupostos: são reais as mudanças ambientais; elas impactam regiões em especial, mas que são interconectadas no planeta; são socialmente desiguais e têm dimensões científicas, tecnológicas, políticas, sociais e éticas. Cabe nos perguntar se a nossa responsabilidade ético-política diante da magnitude da evolução climática é algo realizável ou um discurso utópico, sem condições de concretização?

Tomando como base o livro Terra Pátria de Edgar Morin, entendemos que só conseguiremos efetivamente nos comprometer em ações para a recuperação das questões ambientais, destacadas aqui nas mudanças climáticas, se conseguirmos entender a complexa e interdependente relação entre o homem e a natureza. Essa passa pela compreensão do sentimento de pertença que une o ser humano à sua pátria, a Terra (Morin, 2005).

Um efetivo diálogo deve, portanto, pôr em movimento os jovens das mais diferentes culturas, para fazê-los comunicarem-se. Como eles sentem a magnitude do aquecimento global e sua evolução? Mais diretamente, quais perguntas eles proporiam aos formuladores de políticas? Em que nível é preciso agir? Qual a sua responsabilidade? Essas perguntas orientaram o projeto internacional, intitulado "Pacto Mundial de Jovens pelo Clima", realizado com apoio institucional do Centre Edgar Morin, da École des Hautes Études em Sciences Sociales/Centre National de la Recherche Scientifique (EHESS/CNRS), Paris, França, desde 2014, e auspício da Unesco e outras instituições de pesquisa.

O estudo é realizado na América Latina e Central, África, Oriente Médio, Europa e Leste Europeu, Ásia e Pacifico Sul. Concomitantemente, ações são desenvolvidas em escolas de São Paulo, Acre e Brasília, no Brasil e em mais 133 grupos, de 25 países, dentre eles: França, Portugal, Colômbia, Espanha, Grécia; Senegal, Burkina Faso, Haiti, Chile, Equador, Peru, Estados Unidos, Nepal, Brasil e outros. Em alguns países, a pesquisa é realizada em mais de uma região ou cidade, como é o caso da França e do Chile, e conta, atualmente, com a participação de 5.078 estudantes, ao redor do mundo ${ }^{\text {ii }}$.

O objetivo mais amplo desse estudo implica o aprofundamento e o conhecimento do jovem a respeito das mudanças climáticas, bem como suas escolhas e seus compromissos sociais, éticos e políticos diante dessa situação. Sendo assim, buscamos sensibilizá-los para que se conscientizem dos efeitos das alterações climáticas, de modo a estabelecerem ações responsáveis para o exercício da cidadania planetária; bem como desafiá-los a pensar sobre a governança climática global e os seus diferentes níveis de organização; a formulação de propostas em função de um pacto mundial a favor da preservação do Planeta para apresentação na Conferência Mundial sobre Mudanças Climáticas de 2019. É claro que o nosso objetivo não é tornar os jovens especialistas em mudança climática, mas sim que estejam conscientes das consequências ambientais, sociais, econômicas, políticas e éticas dos efeitos do aquecimento global.

Como podem os fenômenos complexos da mudança climática tornar-se inteligíveis aos estudantes para que eles possam se tornar atores conscientes e ativos? 
Quando o projeto para uma conferência climática em Paris (COP21) foi anunciado, decidimos desenvolver um programa de pesquisa-ação ("Global Youth Climate Pact") voltado para estudantes do ensino médio cujo objetivo era explorar o imaginário social dos jovens, ou seja, a forma como os fenômenos climáticos são representados e como esses jovens, de forma mais sistemática, se combinam, articulam e podem contribuir para as discussões sobre aquecimento global.

Mudar as práticas pedagógicas para uma compreensão múltipla das questões da mudança climática tem implicações em muitos níveis e são transversais, variando da transferência de conhecimento para a aderência ao pensamento crítico, por parte dos alunos, aos impactos tangíveis nas comunidades e no meio ambiente (Sterling, 2004, Tuck e Mckenzie, 2014, Mccoy, 2014).

Estamos convencidos de que os modos tradicionais de transmissão do conhecimento são obstáculos ao diálogo, ao despertar de um conhecimento mais atrativo, mais consciente e mais focado de ação (Latour, 2015). O futuro requer estudar eventos específicos para os efeitos das mudanças climáticas através de uma variedade de saberes disciplinares simultâneos: físicos, biológicos, sociais, ecológicos, econômicos etc.

Compartilhamos do pensamento complexo de Edgar Morin, que se opõe ao reducionismo, promovendo a religação dos saberes, numa proposta que une e não separa os diversos aspectos presentes no universo. Nesse sentido, consideramos as contradições inerentes à condição humana e um caminho que seja solidário e ético (Petraglia, 2013; 2011).

É por isso que os saberes sobre as mudanças climáticas devem ser organizados de forma multidimensional, ou seja, superando as leituras puramente disciplinares, mas aberto à abordagem multi e transdisciplinar. As percepções e as representações que temos dos efeitos da mudança climática, assim como as ameaças reais, imediatas e potencialmente irreversíveis à sociedade humana, devem estar situadas no centro de nossa vida (Searle, 1995).

Esse texto é um recorte que aborda a conclusão da primeira fase da pesquisa, realizada em 2014 e 2015, com base nas investigações continuadas, sistematizações e divulgação de resultados. As reflexões apresentadas são resultantes da deliberação do grupo de São Paulo, Brasil, sobre o combate às mudanças climáticas, que foram encaminhadas à COP21, em Paris, embora as propostas apresentadas pelos brasileiros tenham convergência com os jovens de outros países participantes.

Pode-se dizer que acreditamos ser importante conhecer como os jovens de diferentes regiões e diversificadas culturas sentem a magnitude das mudanças climáticas e a sua evolução, já que serão eles os gestores do Planeta, daqui a alguns anos. São essas prerrogativas e questões, cujas respostas estamos perseguindo, que justificam a relevância social e acadêmica desta pesquisa. Como ponto de partida, definimos como base para o diálogo, três ideias: consciência planetária, responsabilidade e esperança.

\section{Mudanças climáticas: consciência planetária, responsabilidade e esperança}

Há uma urgência em refletir criticamente sobre a realidade da crise ambiental, no que tange aos efeitos das mudanças climáticas. O foco é a busca de uma sociedade 
sustentável movida pelas gerações presentes no cuidado responsável com o ambiente em que vivem, tomando consciência de transições incertas para as futuras gerações.

Um dos desafios para entender os impactos das mudanças climáticas é como converter a noção de que as consequências assumirão diferentes formas em diferentes lugares. De fato, em alguns casos, isso se tornará óbvio devido ao recuo das geleiras (Antártida) e à diminuição do fluxo dos rios. Em outros lugares, isso envolverá um aumento na temperatura (uma onda de calor na Índia, na região de Magadh, por exemplo), o surgimento de novas espécies ou mudanças nas culturas tradicionais e, em outros, uma maior frequência de secas e tempestades.

Ao compartilhar suas vivências, os alunos concordam com os conceitos. Por exemplo, o que os alunos pensam sobre a mudança climática? Essa é a pergunta para a qual buscamos respostas junto aos jovens das muitas escolas de ensino médio que visitamos e consultamos nas reuniões. Queríamos colocar essas discussões em uma perspectiva que possibilitasse aos estudantes estarem cientes das múltiplas interações entre o ecológico, o econômico, o político e o ético, e como enfrentar os desafios cada vez maiores diante do futuro de nosso mundo global. Quais são as atitudes cívicas para promover localmente a preservação do meio ambiente? O objetivo é aumentar a conscientização sobre os problemas que enfrentaremos em breve, com base em fatos científicos que são comuns a nós quando falamos sobre as mudanças climáticas.

Portanto, o papel do cientista é fundamental como "mediador". Ele não atua para "disseminar" o conhecimento, sem questionar a necessidade da construção do pensamento crítico. Foi proposta uma abordagem de diálogo aberto (grupos de discussão, fórum de discussão), por meio dos quais os estudantes podem trocar ideias, livremente, em vários tópicos. Essa ferramenta metodológica participativa permite uma grande liberdade de tom e não é experimentada como discurso de especialistas ou de moralistas.

Nessa perspectiva, refletimos sobre as mudanças climáticas, a partir da constatação de Morin e Kern, sobre a relação inseparável homem-natureza, quando afirmam (2005, p. 49):

O que é esse planeta, esse grão de poeira cósmica onde emergiu a vida, onde a vegetação produziu o oxigênio de sua atmosfera, onde o conjunto dos seres vivos, espalhando-se por toda a sua superfície, constituiu uma biosfera eco-organizada e autorregulada, onde, originada de um ramo do mundo animal, a aventura da hominização se lançou e se desenvolveu? Esse grão de poeira cósmica é um mundo.

Pode-se utilizar a análise de Morin para avançar na reflexão acerca do mundo contemporâneo globalizado e do modelo dominante de desenvolvimento, pelo qual o ser humano foi disperso pelo planeta, afetando, assim, "destinos, fontes de inovação e de criação em todos os domínios" (2000, p. 65). Esse movimento gerou uma conectividade de relações humanas, diante das quais a investigação dos processos educativos, sociais, econômicos e ambientais expressa a mudança de paradigmas, a possibilidade de um destino comum compartilhado e a construção de modelos mais sustentáveis (Morin e Kern, 2005, Morin, 2015).

Desse modo, é essencial uma consciência pela vida do planeta, dos seres vivos e da vida humana. Depois de passarmos nesses últimos anos por dezenas de convenções, protocolos, declarações e legislações nacionais e internacionais para reverter o quadro 
de agravamento das condições ambientais, constatamos que muitos desses compromissos assumidos ainda não foram implementados.

O ser humano chega ao século XXI com inúmeras crises: econômicas, políticas, humanitárias, ambientais, e o que prevalece nos debates é a preponderância do aspecto econômico junto ao político. A questão ambiental, que propõe outra forma de olhar os problemas da humanidade, não tem sido incluída nas discussões.

Viver neste século nos mostra que "O mundo torna-se cada vez mais um todo. Cada parte do mundo faz, mais e mais, parte do mundo e o mundo, como um todo, está cada vez mais presente em cada uma de suas partes". Assim, o homem "traz em si, sem saber, o planeta inteiro. A mundialização é ao mesmo tempo evidente, subconsciente e onipresente", o que nos mostra o aspecto conflituoso e unificador em sua natureza, uma vez que "o mundo, cada vez mais, torna-se uno, mas torna-se, ao mesmo tempo, cada vez mais dividido" (Morin, 2000, p. 67-69). Desse modo, antagonizam-se as relações em seus múltiplos aspectos.

desde os anos de 1970, descobrimos que os dejetos, as emanações, as exalações de nosso desenvolvimento técnico-industrial urbano degradam a biosfera e ameaçam envenenar irremediavelmente o meio vivo ao qual pertencemos: a dominação desenfreada da natureza pela técnica conduz a humanidade ao suicídio (Morin, 2011, p. 61-62).

Uma consciência climática está, portanto, tornando-se uma necessidade para generalidades. A fragmentação do conhecimento é um discurso cada vez mais simples sobre as consequências da mudança climática. Por conseguinte, é necessário mobilizar o máximo possível, por um lado, as apostas objetivas, locais, regionais e globais, e, por outro, inventar novas formas de agir em conjunto. A apropriação dessas questões visa produzir e contextualizar o conhecimento a partir de uma perspectiva de inteligência criativa em favor do surgimento de uma consciência global.

$\mathrm{O}$ uso indiscriminado dos recursos do planeta e sua consequente degradação tornam a vida cada vez mais insustentável, principalmente quando se constata a agonia de nosso planeta, como nos apontam Morin e Kern: "Eis-nos aqui num universo em que certamente muitos enigmas serão elucidados, mas que jamais voltará à sua antiga simplicidade mecânica, que recuperará seu centro solar, e no qual aparecerão outros fenômenos ainda mais espantosos que acabamos de descobrir” (2005, p. 47-48).

Disso decorre que o ser humano precisa compreender o seu pertencimento à Terra, na estimativa do seu estar em seu habitat, ou seja "todas as partes do mundo se tornaram solidárias, sem, contudo, ocultar as opressões e a dominação que devastaram a Humanidade e que ainda não desapareceram" (Morin, 2011, p. 17). Perguntas precisam ser feitas para que nos conscientizemos das reais necessidades do homem e do meio ambiente, para que decisões sejam tomadas levando em conta não apenas a ideia de pertencermos a uma cultura, mas de que somos seres terrenos interdependentes da natureza.

Não é suficiente a constatação de uma crise ambiental planetária, torna-se necessário compreender a ideia de estar na terra, um espaço do bem comum. Então, "É preciso abandonar a ideia simplista de que o progresso técnico/econômico é a locomotiva à qual estão atrelados os progressos sociais, políticos, mentais e morais" e "muitos ganhos foram pagos com perdas" (Morin, 2003, p. 18). Assim sendo, o 
momento exige uma regeneração do bem comum e a consequente reconciliação planetária dos humanos ao seu habitat. Nesse ponto, Morin nos aponta que

Por toda parte reina agora o sentimento, difuso ou agudo, do incerto. Por toda parte firma-se a consciência de que não estamos nos momentos finais da história que antecedem sua grande planificação. Por toda parte desapareceram os balizamentos em direção ao futuro. $\mathrm{O}$ mundo não vai nem bem nem mal, vai aos trancos e barrancos, de solavanco em solavanco, sem estar ainda nem totalmente nem para sempre submerso pela barbárie. A nave Terra navega pela noite bruma numa aventura desconhecida (2003, p. 19).

O primeiro passo a ser dado para enfrentar essa situação é a urgente necessidade de uma consciência planetária: "Donde uma tomada de consciência progressiva, que encontrou sua manifestação no Rio de Janeiro em 1992, da necessidade vital, para a humanidade inteira, de salvaguardar a integridade da Terra" (Morin e Kern, 2005, p. 28).

Tal iniciativa requer em cada ser humano uma consciência indicada por Morin (2011, p. 66), "que reconhece a unidade na diversidade"; que trata na esfera do viver planetário como um "habitar com todos os seres mortais, a mesma esfera viva (biosfera)"; que lida com a "responsabilidade e a solidariedade para com os filhos da terra"; e na condição humana, no "exercício complexo do pensamento" que dá condições para a autocrítica humana e a compreensão mutua."

O ser humano nunca permanece inerte diante dos problemas da complexa dinâmica da vida. Em decorrência disso, Morin (2011) aponta para a necessidade de entendê-los, a partir de um novo olhar sobre a realidade, e, assim sejamos aptos a desenvolver, recriar e reorganizar um mundo, em que sejamos solidários e cidadãos para um consumo sustentável

É quando a noção de direitos e deveres transcende meros interesses individuais para traduzir uma nova visão de mundo, que reflete a responsabilidade de cada pessoa na construção de valores coletivos plenos, plurais e democráticos que assegurem o bem-estar humano e o respeito a todas as formas de vida em suas mais variadas manifestações (Consumo Sustentável, 2005, p. 7).

Dentre esses direitos, destacamos o de bem viver em um ambiente saudável. Para isso, o ser humano deverá consolidar o princípio de cidadania e sua mobilização para a preservação e construção de valores éticos e universais, condição essencial para a construção de uma sociedade sustentável.

O princípio de responsabilidade deve ser buscado pelos homens e nações. $\mathrm{Na}$ perspectiva de Morin (2011), isso se dá em um cuidado impregnado e responsável dos seres humanos para com a dimensão civilizatória, a harmonia planetária. A diversidade e a unidade da relação humana e do homem com a natureza precisam ser preservadas, bem como suas sociedades e a Terra. Mais que isso, exige a "política do homem, a política de civilização, a reforma do pensamento, a antropoética, o verdadeiro humanismo, a consciência da Terra-Pátria" (Morin, 2011, p. 101). 
Tornar-se responsável envolve consciência planetária com base no fundamento de uma consciência promovida pela ideia da Terra-Pátria, em que os interesses deixam de ser apenas individuais para serem coletivos, através de ações e estratégias de uma cidadania comum a todos e uma vivência solidária. É um exercício feito com a liberdade de fazer escolhas que beneficiem todos os seres do planeta.

Como sabemos, a responsabilidade moral está associada aos efeitos de uma ação decidida livremente. Em outras palavras, a ação de uma pessoa é a causa de um efeito que ela carrega, por isso, é de sua responsabilidade. Por outro lado, essa responsabilidade também pode ser o resultado de algo que não escolhemos. Não podemos, então, ser responsáveis por coisas que acontecem através de nós, sem que as escolhamos. Esse estado de coisas é frequentemente mencionado quando se trata de "assumir" nosso nível de responsabilidade com respeito a interrupções da mudança climática. É, portanto, uma afirmação de natureza moral e/ou ética, muitas vezes criticada pelos defensores de outra narrativa acerca da história da idade geológica: o Antropoceno (Malm, 2017). A tese defendida pelo relato do Antropoceno parece ser "o crescimento da população; se puder ser demonstrado que a queima de energia fóssil é, em grande parte, alimentada pela multiplicação da população humana, a espécie pode realmente ser responsabilizada". Mas até que ponto somos todos responsáveis pelas emissões de gases de efeito estufa dos grandes poluidores por gerações?

Para os jovens, a importância relativa indicada como responsável pelas mudanças climáticas têm vários fatores (ver Figura 1). Por exemplo, 38\% deles consideram que a ação humana é responsável pela mudança climática, mas apontam, ao mesmo tempo, como sendo o principal fator a poluição (emissão de $\mathrm{CO}^{2}$, uso de produtos químicos, etc.).

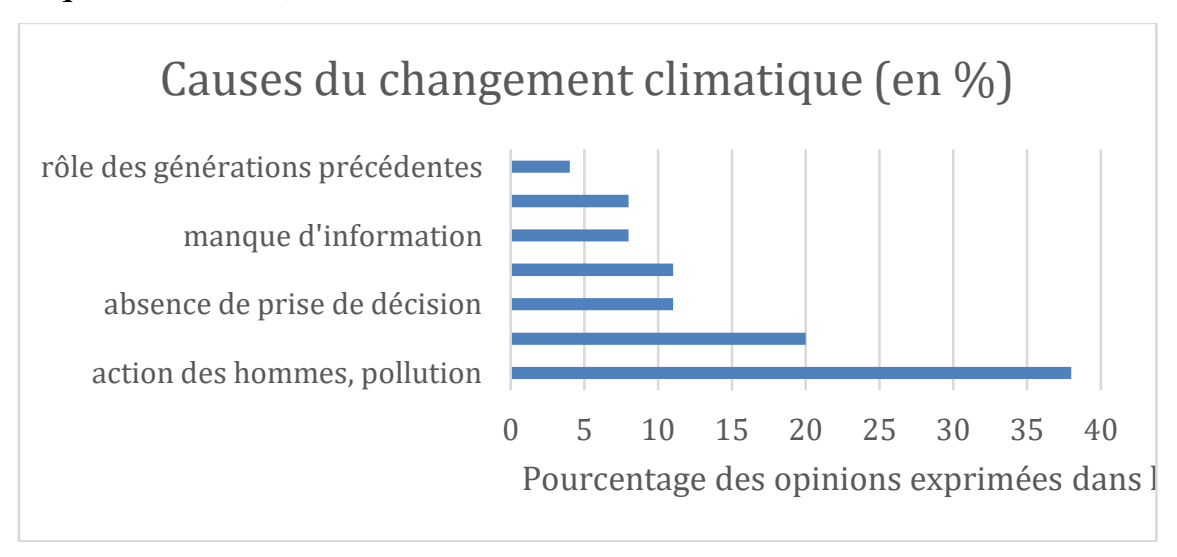

Figura 1. Causas das mudanças climáticas

Nota: Fonte. Pena-Vega (2017)

Na mesma linha, 20\% dos jovens se consideram diretamente responsáveis por seu próprio comportamento. Achamos corajoso que os jovens adolescentes já tenham consciência de "assumir" sua parcela de responsabilidade. No entanto, se somarmos os dois primeiros aspectos importantes de responsabilidade pela mudança climática, $58 \%$ voltam à ação humana. Por outro lado, é importante mencionar que o segundo aspecto significativo é a questão política, com 38\%. De fato, podemos atribuir a falta de tomada de decisão como a baixa conscientização e/ou mobilização da população, a falta de informação abismal na direção dos jovens e, em particular, o business-as-usal inseparável ao reino dos jovens, crescimento e economia fóssil como fatores políticos e o papel das gerações precedentes como causa de responsabilidade. 
A reconstrução e busca de uma consciência planetária pela vida, isto é, pela condição humana do bem-viver, será realizada se questionarmos, como nos aponta Morin, a noção de um desenvolvimento linear, dos modelos prontos e fechados que determinam o futuro, pois "o progresso não está assegurado automaticamente por nenhuma lei da história. O devir não é necessariamente desenvolvimento. O futuro chama-se doravante incerteza" (Morin e Kern, 2005, p. 78).

Para a construção do pensamento do bem-viver, é preciso mobilizar o sentido de que somos sujeitos terrestres, que precisamos significar o mundo e a nossa vida no mundo. Isso se dá desenvolvendo valores e, simultaneamente, ensinando esses valores, o que nos levará à consciência planetária.

Da mesma forma, uma consciência planetária em favor da preservação ambiental se dará na medida em que mobilizamos a esperança, com possibilidades de avanço se buscarmos rever e apresentar como disposição planetária ações tanto individuais quanto coletivas. Nessa perspectiva, é preciso rever e discutir, pois só nós podemos agir em conjunto para mudar esse quadro catastrófico.

É conveniente que o exercício da reflexão e da crítica por parte dos estudantes, acerca das questões ambientais e das mudanças climáticas, passe pela sensibilização sobre grandes questões de nosso tempo. Ao escutá-los, emergem, quiçá, escolhas efetivas de maior comprometimento com a qualidade de vida de todos os seres que vivem no nosso Planeta. Isso é essencial para a construção responsável e para a consolidação da esperança.

Essa transformação se dará com a mudança de paradigma, porque não conseguimos aceitar a crise como uma alternativa. É preciso colocar no currículo da Educação esse tema fundamental e outros, para que se ensine os alunos a enfrentarem os problemas da vida. A Educação precisa ensinar essa consciência de pertencimento à Terra-Pátria.

Nesse sentido, é necessário resistir, voltando a educação para os objetivos humanistas, pelos ideais de liberdade, ética e solidariedade, buscando outra maneira de viver. A resistência se dá pela não aceitação da ordem econômica vigente, ou seja, vale buscar uma economia solidaria, que pode significar uma renovação capaz de movimentar ações individuais e coletivas, na esperança de tentar mudar esse quadro.

Iniciativas educacionais, sociais e ambientais revelam-nos indicadores e caminhos possíveis, pois nos mostram, na prática, que a nossa esperança está em incorporar os princípios tão atuais aos dias de hoje do livro Terra-Pátria de Morin e Kern, em nossa vida. O desafio está em civilizar a Terra, recuperando a unicidade humana e salvaguardando a diversidade. É nesse sentido que se colocam as primeiras observações de nossa pesquisa, em São Paulo.

\section{As três escolas: o campo de investigação e as ações}

Em março de 2014, iniciaram-se no Brasil as atividades na busca de realizar as proposições estabelecidas no projeto de pesquisa. A primeira fase dos trabalhos foi realizada em três escolas da região metropolitana de São Paulo, sendo duas de localização periférica, distintas pela gestão - uma pública e outra privada, e uma terceira escola de localização central e gestão pública. As escolas foram selecionadas segundo 
os critérios de distribuição demográfica observados pelos pesquisadores e pela adesão voluntária de seus gestores, elemento fundamental para os resultados pretendidos.

A instituição pública que se localiza no centro de São Paulo atende muitos alunos, filhos de migrantes nordestinos oriundos dos diversos Estados, além de outra grande parte ser de origem estrangeira, o que explica a dificuldade no processo ensinoaprendizagem em virtude das diferenças linguísticas.

A outra escola pública se localiza na extrema periferia da zona leste do município e atende grande demanda de jovens e crianças, dentre eles muitos órfãos, devido à criminalidade ou à utilização de drogas. A comunidade escolar é oriunda de família de baixa renda, com familiares desempregados, em subempregos, trabalhos temporários, cooperados e diaristas. Apesar das dificuldades enfrentadas, segundo dados fornecidos pela gestão escolar, a comunidade local atribui à escola ótimo conceito, pois: apresenta um quadro de professores que reflete bom ensinoaprendizagem; oferece condições de segurança aos alunos (não utilização de drogas; ausência do tráfico; resolução das situações de conflito); realiza acompanhamento pedagógico constante em relação à vida escolar dos educandos.

A escola privada pesquisada se localiza a $5 \mathrm{~km}$ da escola pública da periferia e o cenário das imediações das duas instituições, dentro do espaço geográfico que as separa, é praticamente o mesmo, apresentando o mesmo perfil no que tange à violência, ao tráfico de drogas e à carência de políticas públicas. Ela atende alunos oriundos de famílias de classe média, foi idealizada a partir da inspiração de educadores, em especial da mantenedora, que acreditavam na necessidade da implantação de uma escola com sua prática voltada à formação de jovens, em que o conhecimento fosse aliado a valores como ética, justiça social e cidadania. A educação oferecida por essa escola visa preparar seus alunos para os desafios do milênio, por meio de uma didática diversificada, utilizando instrumentos tecnológicos de ensino e recursos didáticos aplicados durante as aulas, associados às disciplinas como suporte e aprofundamento dos conteúdos curriculares.

O público envolvido na fase inicial foi de aproximadamente 530 pessoas, entre estudantes do Ensino Médio (faixa etária de 15 a 17 anos), professores e equipe técnica. A duração prevista inicialmente era de dois anos, a partir de 2014, com a apresentação dos resultados na $21^{\mathrm{a}}$ Conferência das Partes (COP21) da Convenção - Quadro das Nações Unidas sobre Mudança do Clima (UNFCCC), em Paris, em 2015, mas, com o firmado Acordo de Paris, fez-se necessário envidar esforços para exigir dos governantes o compromisso assumido de reduzir as emissões de gases de efeito estufa, com os necessários cuidados com o Planeta, assim limitando o aumento da temperatura. Resolveu-se, então, continuar com a pesquisa em uma segunda fase, até 2021.

Para isso, utilizamos abordagens inter e transdisciplinares do conhecimento sobre as mudanças climáticas, para sensibilizar os estudantes à ampliação da consciência e à visão ecológica da realidade.

Compreendendo método como caminho, traçamos estratégias metodológicas multidimensionais, articulando conhecimento e ação através de: estudo da bibliografia indicada e análise dos textos; debate - animação por escola, um ou dois pesquisadores com jovens, a partir da metodologia de grupo focal; discussões coletivas em uma classe de acordo com as escolas selecionadas; pesquisas individuais e coletivas com uma amostra significativa de turmas nas várias escolas sobre o papel de um tribunal da consciência; apresentação de seminários sobre as consequências das mudanças climáticas, com o tema "Os tempos mudam". É uma exposição em três partes: a 
compreensão do clima, os climas do passado, os climas de amanhã; reuniões com as equipes das escolas; reuniões com a equipe de pesquisadores; sistematização; elaboração de relatórios e divulgação dos resultados.

A primeira etapa do projeto teve como objetivo aprofundar o conhecimento acerca de temas ambientais. Combinando horários, de acordo com as peculiaridades de cada escola, partimos para a sensibilização da temática com alunos e professores.

Esta ação desencadeou a realização com os docentes de palestra e workshop, como convite ao desenvolvimento das reflexões ambientais em cada escola. A compreensão das condições ambientais viabilizou a uma das instituições incluir a temática em suas atividades extracurriculares, através de feiras culturais e eventos que envolviam também as famílias dos discentes.

A segunda etapa do projeto foi a sensibilização dos alunos, a qual resultou na identificação de temas de maior interesse a serem aprofundados. Assim, os debates de subtemas se iniciaram com cada turma, de acordo com as escolhas dos alunos. Em cada instituição, foram realizadas palestras com utilização de recursos audiovisuais, seguidos de uma conversa aberta sobre o tema, demandada pelos próprios alunos. As questões que se mostraram recorrentes nas instituições na realização da pesquisa foram temas hídricos e de desmatamento. No primeiro semestre de 2015, quando as atividades interventivas se desenvolveram, o município enfrentava severa crise hídrica, com racionamento de água, inclusive nas regiões onde se encontravam as escolas e residiam os discentes.

Em seguida, iniciamos a terceira etapa do projeto: constituição de grupos focais. Os discentes foram distribuídos em pequenos grupos representativos em número e gênero de cada classe. Em cada instituição, três grupos de 10 a 12 alunos cada foram selecionados por adesão voluntária a um dos três temas, a saber: Cidadania, Mudanças Climáticas e Aquecimento Global.

Essa etapa de trabalho buscou coletar a percepção individual e o grau de compreensão e envolvimento de cada aluno com as questões emergentes relativas aos problemas ambientais em sua realidade, sua cidade, seu país e no mundo. Para isso, o pesquisador portou-se como mero mediador. A metodologia utilizada de grupos focais caracteriza-se como avaliação qualitativa, desconsiderando medidas numéricas e estatísticas. Em abordagem exploratória, o conteúdo do debate é objeto, assim como a interação entre os comunicantes sobre o mesmo conteúdo. Assim, as opiniões produzidas e em produção se testam e se desenvolvem dentro da interação entre os sujeitos, ao mesmo tempo, observadores e observados.

$\mathrm{Na}$ quarta e última etapa, os grupos de jovens se reuniram para debater as diferentes visões apresentadas sobre a mesma temática e para levantar as questões apontadas como sugestões e soluções ambientais de cada escola para debate nas demais. Assim, as questões da escola A, por exemplo, foram levadas para audiência e debate nas escolas B e C, separadamente, produzindo assim o cruzamento das ideias similares e a complementaridade entre as distintas regiões consultadas.

Dessa etapa, foi organizada a coleta de um conjunto de reflexões autorais dos jovens das três escolas, identificando elementos comuns que permitiram compará-las e/ou agregá-las, com a indicação de um representante discente de cada escola a participar de um fórum internacional.

O relatório final da sistematização concentrou os principais achados da pesquisa em 94 propostas sobre 11 temas distintos. São eles: Educação; Justiça, cooperação e 
solidariedade internacional; Gestão e poder público; Direitos Humanos; Transporte e mobilidade urbana; Democracia participativa; Política; Agricultura; Cidadania e consciência planetária; Desperdício e Transição energética.

As turmas dos estudantes das três escolas, em suas propostas, mostraram-nos a importância de pensar globalmente e agir localmente. Entre as ideias, estão: promoção de iniciativas individuais de incentivo e conscientização nas escolas acerca da preservação ambiental local e planetária; criação de um tribunal mundial de crimes contra o ambiente; desenvolvimento da consciência ecológica, de preservação ambiental e planetária, a começar pelas crianças e jovens; inibição de atitudes e atividades depredadoras do meio ambiente, construção de uma lista de reivindicações enviada aos nossos governantes e legisladores, para cobrar o que eles estão fazendo ou vão fazer, e outras. Além disso, foi elaborado um Documento internacional, com a inclusão dessas propostas, discutido na COP21.

A pesquisa aqui apresentada está em desenvolvimento e terá a duração de mais dois anos letivos, até 2021. Neste trabalho, entretanto, apresentamos o recorte das atividades realizadas, bem como os principais resultados dos trabalhos desenvolvidos entre março de 2014 e dezembro de 2015.

Considerando as reflexões desenvolvidas no relatório parcial, podemos inferir que o aprofundamento da temática, através da leitura, dos debates desencadeados no processo desta pesquisa e as questões elencadas em cada escola, na voz de um representante de sua geração, mostrou-se profícua contribuição para o debate sobre as mudanças climáticas e as possíveis formas de se arbitrar problemas ambientais internacionais.

\section{Considerações finais}

Como mostramos, as percepções - consciência - que os jovens têm das mudanças climáticas e suas consequências em termos de ação (adaptação, emergência climática, transição ambiental, etc.) devem ser interpretadas como um grande ponto de virada que os jovens enfrentarão no futuro. As questões que surgem são muitas: os alunos são sensíveis ao conhecimento consciente? Em que escala de tempo/lugar eles colocam os problemas: presente, futuro, local, global? E a responsabilidade como cidadão? Como eles concebem a emergência climática? Todas essas questões carecem de critérios, um modelo único, o surgimento de fenômenos extremos com certa complexidade, incluem pluralidade ou até mesmo heterogeneidade, imaginário, incerteza, desconhecido (Morin, 2017).

Esse projeto nos permitiu levantar desafios para que se possa continuar pesquisando. Um deles diz respeito à necessidade de investigar outros jovens de outras escolas sobre o tema. Por mais que o debate sobre as mudanças climáticas venha se consolidando e sendo incorporado mundialmente nas agendas, é importante destacar a temática na incidência territorial. Nesse sentido, também é essencial sensibilizar as equipes escolares que lidam com jovens para incorporarem em seus currículos as questões ambientais.

É preciso que o debate sobre as mudanças climáticas seja cada vez mais apropriado pelas escolas, para que jovens profissionais possam, no futuro, contribuir com a elaboração de políticas direcionadas a essa temática. Esperamos que os resultados da pesquisa, em 2019 e 2020, com avaliação em 2021, sejam igualmente proveitosos. 


\section{Referências}

Consumo Sustentável (2005). Manual de Educação. Brasília: Consumers International/MMA/MEC/IDEC. Retrieved from http://pt.scribd.com/doc/6755776/Manual-Consumo-SustentavelApresentacao.

Latour, Bruno (2015). Face à Gä̈a. Huit conférences sur le nouveau régime climatique. Paris: La Découverte. Les Empêcheurs de penser en rond.

Malm, Andreas (2017). L'Anthropocène contre l'histoire. Le rechauffement climatique à lère du capital. Paris: La fabrique Editions.

Morin, Edgar (2017). Connaissance, ignorance, mystère. Paris: Fayard.

Morin, Edgar (2015). Penser global. L'humain et son univers. Paris: Editions: Robert Laffont.

Morin, Edgar (2011). Os sete saberes necessários à educação do futuro. Trad. Marisa Perassi Bosco e Edgard de Assis Carvalho. (2 ${ }^{\mathrm{a}}$ ed.). São Paulo: Cortez; Brasília: UNESCO.

Morin, Edgar (2003). Além do progresso. In: Morin, E. e Wulf, C. Planeta: a aventura desconhecida. Trad. Pedro Goergen. São Paulo: Unesp.

Morin, Edgar (2000). A cabeça bem-feita: repensar a reforma, reformar o pensamento. Tradução: Eloá Jacobina. Rio de Janeiro: Bertrand Brasil.

Morin, Edgar e Viveret, Patrick (2013). Como viver em tempo de crise? Tradução Clóvis Marques. Rio de Janeiro: Bertrand Brasil.

Morin, Edgar e Kern, Anne Brigitte (2005). Terra-pátria. Trad. Paulo Neves. (4 ed.). Porto Alegre: Sulina.

Morin, Edgar, Pena-Vega, Alfredo e Paillard, Bernard (2004). Diálogo sobre o conhecimento. Tradução de Maria Alice Araripe Doria; Revisão Técnica de Cleide R. S. de Almeida e Izabel Petraglia. São Paulo: Cortez.

Pena-Vega, Alfredo (2003). O despertar ecológico. Edgar Morin e a ecologia complexa. Tradução: Renato Carvalheira do Nascimento e Elimar Pinheiro do Nascimento. Rio de Janeiro: Garamond.

Pena-Vega, Alfredo, Almeida, Cleide e Petraglia, Izabel (Orgs.) (2011). Edgar Morin: Ética, Cultura e Educação. (4 ${ }^{\mathrm{a}}$ ed.). São Paulo: Cortez.

Pena-Vega, Alfredo (2019). Les sept savoir nécessaires à l'éducation du changement climatique. Prefacio, Maria Fernanda Espinosa, Presidente da Assembleia das Nações Unidas. Potiers. Paris: Edição Atlantique.

Petraglia, Izabel (2013). Pensamento complexo e educação. São Paulo: Editora Livraria da Física.

Petraglia, Izabel (2011). Edgar Morin: educação e a complexidade do ser e do saber. $13^{\mathrm{a}}$ ed. Petrópolis: Vozes.

Searle, R. John (1995). La redécouverte de l'esprit. Paris: Gallimard. 
Sterling Stephen (2004). Higher education, sustainability, and the role of systemic learning. In P. B. Corcoran e A. E. J. Wals. Higher education and the challenge of sustainability (pp. 49-70). Nova Iorque: Kluwer Academic Publishers.

Tuch, Eve, Mckenzie, Marcia e Mccoy, Kate (2014). Land education: indigenous postcolonial and decolonizing perspectives on place and environmental education research. Environmental Education Research, 20(1), 1-20.

\begin{abstract}
i Ver www.globalyouthclimatepact.org
ii O projeto tem a colaboração de pesquisadores voluntários, sob a coordenação científica internacional do Prof. Dr. Alfredo Pena-Vega (Centro Edgar Morin/CNRS da EHESS, Paris, França) e, no Brasil, a coordenação é da Profa. Dra. Izabel Petraglia (Universidade Metodista de São Paulo - UMESP; Grupo de Estudo e Pesquisa em Complexidade - GEPEC). Os pesquisadores, em São Paulo, são: Profa. Dra. Mariangelica Arone; Prof. Ms. Marcel Sena Fernandes e, Profa. Dra. Conceição Aparecida Viude Fernandes, todos membros do GEPEC. Estudantes de mestrado, doutorado e iniciação científica estão sendo inseridos gradativamente.
\end{abstract}

Data da recepção: $25 / 07 / 2019$

Data da revisão: 15/10/2019

Data do aceite: 17/10/2019 